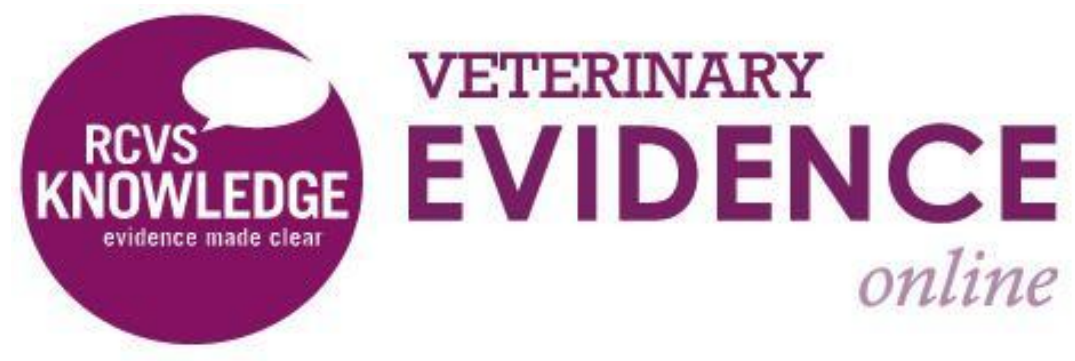

\title{
Are Dogs Fed a Kibble-Based Diet More Likely to Experience an Episode of Gastric Dilatation Volvulus Than Dogs Fed an Alternative Diet?
}

\author{
A Knowledge Summary by \\ Louise Anne Buckley PhD, RVN ${ }^{1^{*}}$ \\ ${ }^{1}$ Harper Adams University, Newport, Shropshire, TF10 8NB
${ }^{*}$ Corresponding Author (Ibuckley@harper-adams.ac.uk)
}

ISSN: 2396-9776

Published: 19 Apr 2017

in: Vol 2, Issue 2

DOI: http://dx.doi.org/10.18849/ve.v2i2.63

Reviewed by: Nicola Ackerman (BSc(Hons), RVN, CertSAN, CertVNECC, VTS(Nutr), A1 V1 MBVNA) and Sue Badger (MEd, Cert Ed, RVN) 


\section{Clinical bottom line}

Most of the studies that attempt to either partially or fully address the PICO contain limitations that mean that they should either be rejected as unable to address the PICO or viewed with caution due to potential bias in the population studied. Of the two studies that remain, the findings conflict. One study found dogs fed a diet containing small particles only ( $<5 \mathrm{~mm}$, mainly dry kibble fed dogs) at greater risk of GDV than those fed a diet containing large particles ( $>30 \mathrm{~mm}$, at least partly non-kibble based). The other study found no significant effect of kibble on GDV risk once other potential risk factors were controlled for in the analysis. Consequently, there is insufficient quality evidence to support the claim that feeding a kibble diet is associated with an increased risk of GDV. However, it is worth noting that no studies found that dogs fed a diet that contained no kibble (dry or moistened) were at increased risk of GDV, and the addition of either table scraps, canned food or non-kibble supplements to the dog's diet reduced the risk in some studies but more research is needed to unpack the implications of this for feeding a kibble diet.

\section{Question}

Are dogs fed a kibble-based diet more likely to experience an episode of gastric dilatation volvulus than dogs fed an alternative diet?

\section{Clinical Scenario}

A client attends the veterinary clinic with a breed of dog considered to be at a high risk of gastric-dilatation volvulus (GDV). During the consultation, the dog's dietary needs are being discussed. The client says that they have been on an internet discussion forum and other owners have warned them that feeding a dried, kibblebased diet will put their dog at an increased risk of having an episode of GDV. The client asks you, the veterinary practitioner, what the evidence is for this claim.

\section{The Evidence}

The literature searches uncovered six papers (Glickman et al., 1997; Elwood, 1998; Theyse et al., 1998; Raghavan et al., 2004; Pipan et al. 2012; Uhrikova et al., 2015) that either partially or fully addressed the PICO question. These papers do not neatly address the PICO as the dogs studied either all/almost all were fed a kibble only diet or kibble as the primary diet (Glickman et al., 1997; Ragavan et al., 2004) or fed different diet types in combination (Theyse et al, 1998; Uhrikova et al., 2015) and/or assessed diet in terms of the maximum size of the food particles (Theyse et al, 1998; Uhrikova et al., 2015) that comprised the diet fed so the summaries of the experimental details should be examined for further understanding.

Of these papers, one paper found feeding a kibble diet increased GDV risk (Pipan et al., 2012) but failed to match dogs for size between groups so the findings may have been biased if large breed dogs are more likely to be fed kibble-based diets. One paper (Uhrikova et al., 2015) found no effect of feeding a kibble only diet, but dogs fed a diet containing some kibble were more likely to experience a GDV than dogs fed a diet with no kibble. However, in this study the median weight of the dogs in the control group was significantly different to those in the two GDV groups (groups based on GDV - survival: 1. Survived, 2. Died) making this study susceptible to the same criticism leveled at Pipan et al. (2012). However, the direction of effect is not reported (i.e. it is not clear whether the dogs in the control group were lighter or heavier than one or both of the GDV groups). Raghavan et al. (1997) claimed there was no effect of feeding a kibble diet but all, bar two, dogs $(n=318)$ in their study were being primarily fed a dry, kibble-based diet so there was no alternative diet control group to compare to and thus the effect of feeding kibble not amenable to meaningful statistical analysis. In Elwood (1998), the main statistical analysis demonstrated no effect of kibble on GDV risk, but the initial analysis did identify kibble as a potential risk factor. However, feeding a diet that contained no kibble 
reduced the risk of GDV (Uhrikova et al., 2015), as did feeding table scraps (but not canned commercial food) as part of the diet (Glickman et al., 1997) or adding fish or egg supplements to the diet (Pipan et al., 2012). Several studies (Glickman et al., 1997; Elwood, 1998; Raghavan et al., 2004; Uhrikova et al., 2015) reported collecting data on dry and moistened kibble diets, but only one paper (Glickman et al., 1997) reported their findings specifically in relation to dry kibble versus moistened kibble. They found that moistening the dry kibble diet before feeding did not affect risk of GDV compared with feeding dry kibble only.

Both of the papers (Theyse et al., 1998; Uhrikova et al., 2015) that focused on particle size present within the diet found that feeding a diet with small particles of food only $(<5 \mathrm{~mm}$; Theyse et al., 1998) or medium particles of food as a maximum $(5-30 \mathrm{~mm}$, but not small particles less than < 5mm; Uhrikova et al., 2015) increased risk of GDV compared with dogs fed a diet containing some large particles of food (>30mm). In these studies, any diet containing particles greater than $>30 \mathrm{~mm}$ contained none-kibble components (either partially or exclusively). In the Theyse et al. (1998) study, 83\% (19/23 dogs) in the < 5mm category were fed a kibble only diet. No studies identified feeding a diet that did not contain kibble as a risk factor for GDV.

\section{Summary of the evidence}

\section{Pipan (2012)}

\begin{tabular}{|c|c|}
\hline Population: & $\begin{array}{l}\text { Privately owned dogs (any breed or mix, both sexes, neutered and } \\
\text { entire) across a wide geographic area. } \\
\text { The survey was potentially available to English speaking dog owners } \\
\text { with access to the internet in any country worldwide. }\end{array}$ \\
\hline Sample size: & $\begin{array}{l}2551 \text { surveys included in the analysis: } \\
\text { - Control group (dogs without a GDV): } 1437 \text { respondents } \\
\text { - Gastric dilatation-volvulus group (GDV): } 1114 \text { respondents }\end{array}$ \\
\hline Intervention details: & $\begin{array}{l}\text { Online survey based study, with ad hoc convenience sampling of dog } \\
\text { owners. } \\
\text { The questionnaire was divided into three sections: } \\
\text { 1. Demographic information (year of birth, breed, sex, neuter } \\
\text { status, and purpose of the dog; country and postcode of } \\
\text { respondent). Whether the dog had ever had a GDV that } \\
\text { required surgical intervention. This latter question was used } \\
\text { to divide dogs into the control group and the GDV group. } \\
\text { However, the authors then also included within the GDV } \\
\text { group dogs that did not have surgery, or died / were } \\
\text { euthanised without surgery but were considered to have a } \\
\text { GDV (whether confirmed or presumed). } \\
\text { 2. GDV group: a series of } 44 \text { questions divided into } 4 \text { categories } \\
\text { were asked that covered: } \\
\text { i. Dog specific factors } \\
\text { ii. } \quad \text { Management factors } \\
\text { iii. Environmental factors } \\
\text { iv. Personality factors } \\
\text { 3. Control group: The same questions were asked of the } \\
\text { control group dog owners as were asked of the GDV group, } \\
\text { with the exception that they were not asked any questions }\end{array}$ \\
\hline
\end{tabular}




\begin{tabular}{|c|c|}
\hline & $\begin{array}{l}\text { about the GDV episode (as the dogs had not experienced a } \\
\text { GDV). They were asked one additional question (had the dog } \\
\text { had a prophylactic gastroplexy?). These changes reduced the } \\
\text { total number of questions asked to } 32 \text {. }\end{array}$ \\
\hline Study design: & Cross-sectional study \\
\hline Outcome studied: & $\begin{array}{l}\text { The outcome measure was a GDV episode that required surgical } \\
\text { intervention in the dog's history. The study looked for factors that } \\
\text { were associated with an increased incidence of GDV in the } \\
\text { population studied. } \\
\text { Of relevance to this PICO, the authors' asked owners: } \\
\text { 1. What type of diet the dog was fed? (dry kibble, canned food, } \\
\text { raw commercial, cooked homemade, raw homemade) } \\
\text { 2. Whether the dog's diet was supplemented with any of the } \\
\text { following? (eggs, cod liver oil, fish, cooked chicken, raw } \\
\text { chicken, cottage cheese, yoghurt }{ }^{*} \text { ) } \\
\text { 'plus others not clearly relevant to changing the diet texture or } \\
\text { moisture content. }\end{array}$ \\
\hline $\begin{array}{r}\text { Main findings: } \\
\text { (relevant to PICO question): }\end{array}$ & $\begin{array}{l}\text { The primary relevant finding was that feeding a kibble diet } \\
\text { significantly increased the risk of GDV (Odds ratio: } 1.7,95 \% \\
\text { confidence interval: } 1.21-2.39, \mathrm{P}=0.002 \text { ). } \\
\text { Adding the following supplements to the dog's diet significantly } \\
\text { reduced the risk of GDV: } \\
\quad \text { - Fish dietary supplements (Odds ratio: } 0.51,95 \% \text { confidence } \\
\text { interval: } 0.37-0.70, \mathrm{P}<0.001 \text { ) } \\
\text { - Egg dietary supplements (Odds ratio: } 0.57,95 \% \text { confidence } \\
\text { interval: } 0.44-0.73, \mathrm{P}<0.001 \text { ) } \\
\text { Feeding table scraps had no effect on GDV risk. The authors mention } \\
\text { this finding in the discussion and there is no statistical output } \\
\text { reported. }\end{array}$ \\
\hline Limitations: & $\begin{array}{l}\text { The incidents of GDV were retrospective so owners may have } \\
\text { already altered their dog's diet (either type or by the addition of } \\
\text { supplements), on the basis of veterinary recommendation or lay } \\
\text { research. The authors do not outline whether owners were asked to } \\
\text { complete the form based on the dog's diet at the time (or } \\
\text { preceding) the GDV, or, the present time, or not given a time frame } \\
\text { to use. } \\
\text { The study recruited dogs of any size, breed, and age. There was no } \\
\text { attempt to match control and GDV cases across other dimensions } \\
\text { that may have been relevant (e.g. breed, size, and/or age) in the } \\
\text { study design or analysis and this may have affected the results. For } \\
\text { example, are owners of large or giant breed dogs more likely to feed } \\
\text { a dry kibble diet than owners of small and medium sized dogs (e.g. }\end{array}$ \\
\hline
\end{tabular}




\begin{tabular}{|c|c|}
\hline & $\begin{array}{l}\text { for reasons of economy)? And, if so, is any significant effect of kibble } \\
\text { real or an artefact of the fact that large and giant breed dogs are } \\
\text { more likely to have a GDV than small breed dogs? This would } \\
\text { potentially skew the data in the direction reported by the authors. } \\
\text { This failure to match control and GDV cases across other potentially } \\
\text { relevant dimensions is one of the biggest drawbacks of this study } \\
\text { and it would have been more useful if the study authors had } \\
\text { restricted the study only to at risk breeds and / or dogs over a } \\
\text { certain size (large / giant breeds) when answering this research } \\
\text { question. } \\
\text { The authors do not report investigating interactions between diet } \\
\text { type and supplements in terms of increased or decreased risk. E.g. } \\
\text { did adding fish to the diet of kibble fed dogs reduce the risk of GDV, } \\
\text { but have no effect on the risk of GDV of canned fed dogs? Etc. This } \\
\text { limits the ability of the reviewer to interpret the supplement findings } \\
\text { in relation to the PICO or develop hypotheses to explain the study's } \\
\text { primary diet type finding. }\end{array}$ \\
\hline \multicolumn{2}{|l|}{ Theyse (1998) } \\
\hline Population: & Great Danes. \\
\hline Sample size: & $\begin{array}{l}109 \text { dogs: } \\
-\quad 38 \text { dogs that had presented at the authors' vet clinic with a } \\
\text { GDV } \\
\text { - } \quad 71 \text { dogs owned by members of a Great Dane breed society }\end{array}$ \\
\hline Intervention details: & $\begin{array}{l}\text { Clinic records were retrospectively searched for cases of acute GDV } \\
\text { in Great Danes presented to the clinic over a } 14 \text { year period (January } \\
1981 \text { - December 1994). No information is provided on the fate } \\
\text { (survived or died) of the dogs that attended the clinic. } \\
\text { Control dogs were obtained by contacting a Great Dane breed } \\
\text { society. } \\
\text { Owners of both groups of Great Danes were asked to complete a } \\
\text { questionnaire that asked owners about their feeding and exercise } \\
\text { regime. } \\
\text { Demographic information was also recorded (age, sex, neuter status; } \\
\text { and, for GDV dogs only, type of food eaten before the GDV episode). } \\
\text { Of particular relevance to this PICO, owners were asked about their } \\
\text { dogs' diet and asked to provide a sample of the diet fed to their dog. }\end{array}$ \\
\hline Study design: & $\begin{array}{l}\text { A cross sectional study (based on the RCVS Knowledge Knowledge } \\
\text { Summary guide); the authors' describe it as a case-control study. }\end{array}$ \\
\hline Outcome studied: & $\begin{array}{l}\text { The outcome of interest was whether the dogs had had an episode } \\
\text { of GDV. The authors were then interested in identifying risk factors } \\
\text { that were associated with a GDV outcome. }\end{array}$ \\
\hline
\end{tabular}




\begin{tabular}{|c|c|}
\hline & $\begin{array}{l}\text { Of relevance to this PICO, the authors' asked about the dog's diet } \\
\text { and requested to provide a sample of the diet they fed their dog. All } \\
\text { owners in the study complied ( } n=109 \text { ). Because the diet fed was } \\
\text { often a combination of commercial brand(s) and/or home - } \\
\text { prepared food and meat, the authors altered the risk factor/variable } \\
\text { studied to maximum food particle size within the sample ration } \\
\text { provided. } \\
\text { An ordinal scale was used: } \\
\text { 1. <5mm (kibble or kibble and ground home-prepared food) } \\
\text { 2. 5-30mm (dry dog food and/or canned dog food and/or } \\
\text { small, cut up pieces of home-prepared food). The dry dog } \\
\text { food was a mix of meat chunks, flakes and grains. } \\
\text { 3. > 30mm (commercial dog food and/or home-prepared food, } \\
\text { plus large chunks of meat). The commercial dog food was } \\
\text { either kibble, dry, or canned dog food. }\end{array}$ \\
\hline $\begin{array}{r}\text { Main findings: } \\
\text { (relevant to PICO question): }\end{array}$ & $\begin{array}{l}\text { Dogs fed a diet that contained some particles that were greater than } \\
30 \mathrm{~mm} \text { were } 75 \% \text { less likely to have a GDV episode than dogs fed a } \\
\text { diet in which the maximum particle size was }<5 \mathrm{~mm} \text { (Odds ratio: - } \\
0.25, \mathrm{P}=0.017 \text { ). } \\
\text { A significant difference in risk of GDV was not observed between } \\
\text { dogs in the }<5 \mathrm{~mm} \text { category and dogs in the } 5-30 \mathrm{~mm} \text { category. No } \\
\text { further output is provided here. } \\
\text { Eighty three percent }(19 / 23 \text { ) dogs in the }<5 \mathrm{~mm} \text { category were fed a } \\
\text { dry kibble diet only. }\end{array}$ \\
\hline Limitations: & $\begin{array}{l}\text { The authors retrospectively searched clinic records for GDV cases in } \\
\text { Great Danes between } 1981 \text { and } 1994 \text { and owners of affected dogs } \\
\text { were contacted to complete a questionnaire that retrospectively } \\
\text { assessed feeding and exercise regime and to provide a diet sample. } \\
\text { - Thus, owners were often being asked to recall information } \\
\text { about their dog's exercise and diet regime many years (up to } \\
\text { circa } 13 \text { years if they conducted their retrospective search in } \\
\text { 1994/5) after the GDV episode and/or likely death of their } \\
\text { dog. Factual recall is likely to be poor under these } \\
\text { circumstances and this will have implications for accuracy of } \\
\text { both diet type recall and sample provision. Whereas, control } \\
\text { group owners were probably being asked about an existing, } \\
\text { current dog that they own (not enough information is } \\
\text { provided to say this for certain). } \\
\text { Alternatively, dietary and exercise regime modifications may } \\
\text { have been implemented post-acute GDV episode (in the } \\
\text { dogs that survived) and these reported by the owner as their } \\
\text { regime. This would prevent accurate measurement of risk } \\
\text { factors associated with GDV development. There is not } \\
\text { enough detail provided by the authors to allow this } \\
\text { possibility to be evaluated. } \\
\text { There is not enough information provided regarding the way }\end{array}$ \\
\hline
\end{tabular}




\begin{tabular}{|c|c|}
\hline & $\begin{array}{l}\text { that the owners fed their dogs the diet type. For example, } \\
\text { does dry kibble diet refer to the type of food or the way in } \\
\text { which the dry kibble diet was fed (e.g. was it fed 'dry' or fed } \\
\text { 'soaked'?). If the kibble diet was fed soaked by the owners, } \\
\text { did the researchers soak the kibble before measuring the } \\
\text { particle size? Was this information extracted from owners? }\end{array}$ \\
\hline \multicolumn{2}{|l|}{ Glickman (1997) } \\
\hline Population: & Owned dogs within the USA. \\
\hline Sample size: & 202 dogs (101 matched case-control pairings). \\
\hline Intervention details: & $\begin{array}{l}\text { Several veterinary practices were contacted to complete a clinical } \\
\text { data sheet for dogs that were presented at the clinic, diagnosed with } \\
\text { GDV, and whose owners were willing to be contacted by } \\
\text { researchers. Vets were asked to also identify a similar dog (matched } \\
\text { for age and breed if pure breed, or age and weight if cross bred). } \\
\text { Researchers provided their own case control dog through the } \\
\text { university veterinary hospital if vets were unable to. } \\
\text { All owners (GDV, and case-matched control) were interviewed by } \\
\text { phone. Data on the following areas were collected: } \\
\text { - The owner of the animal } \\
\text { - Environmental factors } \\
\text { - Clinical history } \\
\text { - Physical activities } \\
\text { - Dietary factors } \\
\text { - Personality and temperament } \\
\text { Two types of questions were asked: } \\
\text { 1. Those designed to evaluate the dog in the } 8 \text { hours preceding } \\
\text { the GDV episode (GDV dogs) or telephone interview (case- } \\
\text { dogs) } \\
\text { 2. Those designed to evaluate the dog's behavior, diet, etc } \\
\text { more generally over the preceding year. } \\
\text { Of particular importance to this PICO was diet and nutrition. The } \\
\text { authors do not set out within the methodology what type of data } \\
\text { possible to identify that the owners were asked about: } \\
\text { - Diet type (dry, canned) } \\
\text { - Use of dietary supplements } \\
\text { Whether the dry food was moistened }\end{array}$ \\
\hline Study design: & $\begin{array}{l}\text { A cross sectional study (based on the RCVS Knowledge Knowledge } \\
\text { Summary guide); the authors' describe it as a case-control study. }\end{array}$ \\
\hline Outcome studied: & $\begin{array}{l}\text { The outcome variable was an episode of GDV. The authors looked } \\
\text { for risk factors associated with this. Of relevance to this PICO, the } \\
\text { potential risk factor evaluated included: }\end{array}$ \\
\hline
\end{tabular}




\begin{tabular}{|c|c|}
\hline & $\begin{array}{l}\text { - Diet type (canned, dry) } \\
\text { Of possible relevance to this PICO, the following additional potential } \\
\text { risk factors were evaluated: } \\
\text { - Use of dietary supplements } \\
\text { - } \quad \text { Whether the dry diet was moistened or not } \\
\text { - } \quad \text { Feeding of table scraps }\end{array}$ \\
\hline $\begin{array}{l}\text { Main findings: } \\
\text { (relevant to PICO question): }\end{array}$ & $\begin{array}{l}\text { Almost all of the dogs, irrespective of GDV development, were fed a } \\
\text { dry diet on a regular basis so the authors concluded that it was not } \\
\text { possible to evaluate dry diet as a risk factor. } \\
\text { Feeding canned dog food did not significantly affect risk of GDV } \\
\text { (odds ratio: } 0.72,95 \% \text { confidence interval: } 0.32-1.42, P=0.34)^{*} \text {. } \\
\text { Feeding table scraps significantly decreased the risk of GDV (odds } \\
\text { ratio: } 0.41,95 \% \text { confidence interval: } 0.17-0.96, P=0.04)^{*} \text {. } \\
\text { Moistening the dry dog food did not affect risk of developing a GDV } \\
\text { (p >0.25, no other values reported). } \\
\text { Very few dogs in either group were fed supplements, so the authors } \\
\text { concluded that it was not possible to evaluate supplement use as a } \\
\text { risk factor. } \\
\text { * Please note: in the original identification of potential risk or } \\
\text { protective factors to include in the multivariate final analysis, the } \\
\text { authors used the following P value thresholds to determine } \\
\text { potentially significant factors: } \\
\quad \text { - P< } 0.25 \text { : for the preliminary univariate analysis. } \\
-\quad \text { P }<0.20 \text { : for the intermediary multivariate analysis. } \\
\text { These are very generous thresholds that increase the risk of a type } 1 \\
\text { error (a false positive). While the authors are using this threshold as } \\
\text { an intermediary step to determine factors for inclusion in the final } \\
\text { statistical models, readers of the paper who are not familiar with } \\
\text { statistics may over-interpret tables } 1 \text { (pg. } 199 \text { ) and } 2 \text { (pg. } 200 \text { ) of this } \\
\text { paper, including drawing the inference that feeding canned food } \\
\text { significantly decreased the risk of a GDV. }\end{array}$ \\
\hline Limitations: & $\begin{array}{l}\text { It is not clear whether the GDV group included dogs that were } \\
\text { deceased as a consequence of the first GDV episode. It is possible } \\
\text { that referring veterinarians would not approach owners of dogs that } \\
\text { died or, alternatively, that owners whose dogs died were more or } \\
\text { less willing to be interviewed. This may have introduced bias into the } \\
\text { data set if survival rate from a GDV is associated with diet type fed. }\end{array}$ \\
\hline \multicolumn{2}{|l|}{ Elwood (1998) } \\
\hline Population: & $\begin{array}{l}\text { Irish Setter dogs (both sexes, neutered and entire) owned by } \\
\text { members of UK Irish Setter Breed Clubs. }\end{array}$ \\
\hline Sample size: & $\begin{array}{l}669 \text { dogs: } \\
-75 \text { dogs that had had an episode of gastric dilatation and/or }\end{array}$ \\
\hline
\end{tabular}




\begin{tabular}{|c|c|}
\hline & $\begin{array}{ll} & \text { volvulus } \\
\text { - } & 594 \text { control dogs }\end{array}$ \\
\hline Intervention details: & $\begin{array}{l}\text { A questionnaire was sent to members of UK Irish setter breed clubs, } \\
\text { and requested to complete one form per Irish Setter that they had } \\
\text { owned in the last ten years. } \\
\text { Demographic information included age, sex, neuter status and } \\
\text { whether the dog had ever had an episode of bloat/GDV. } \\
\text { Owners were requested to complete the answer by providing data } \\
\text { for the dog that applied at the time of the first GDV episode (GDV } \\
\text { dogs) or current data (control dogs). } \\
\text { A range of questions were asked about potential risk factors. These } \\
\text { included a range of dietary, environment, temperament and } \\
\text { exercise-related factors. } \\
\text { Of specific relevance to this PICO, the owners were asked what diet } \\
\text { they fed their dog. }\end{array}$ \\
\hline Study design: & Cross-sectional study. \\
\hline Outcome studied: & $\begin{array}{l}\text { The outcome variable was whether an episode of GDV occurred. The } \\
\text { study then asked about a range of variables, in order to identify risk } \\
\text { factors that were associated with a GDV episode. } \\
\text { Of specific relevance to this PICO, the owners were asked what they } \\
\text { fed their dog: } \\
\text { - Dry (unsoaked) } \\
\text { - Dry (soaked) } \\
\text { - Meat and biscuits } \\
\text { - Proprietary tinned food (alone) } \\
\text { - Proprietary tinned food (with biscuit) } \\
\text { - Other (the owner was asked to provide details) }\end{array}$ \\
\hline $\begin{array}{l}\text { Main findings: } \\
\text { (relevant to PICO question): }\end{array}$ & $\begin{array}{l}\text { Dogs fed a dry diet was no more likely to have an episode of GDV } \\
\text { than dogs fed other types of diet (Odds ratio: } 1.97,95 \% \text { confidence } \\
\text { interval: } 0.7-5.56, P>0.05 \text { ). } \\
\text { Nb. The initial univariate statistical analysis found that dogs that } \\
\text { were fed a dry diet were significantly more likely to experience a } \\
\text { GDV than dogs not fed a dry diet (Odds ratio: } 2.13,95 \% \text { confidence } \\
\text { interval: } 1.01-4.5 ; P<0.05) \text {. However, once incorporated into a } \\
\text { multivariate analysis that included, where possible, the other risk } \\
\text { factors previously identified, the adjusted risk factor was no longer } \\
\text { significant. It is not clear which other risk factors were definitively } \\
\text { included in this multivariate analysis. }\end{array}$ \\
\hline
\end{tabular}




\begin{tabular}{|c|c|}
\hline Limitations: & $\begin{array}{l}\text { The authors requested owners complete a questionnaire form for } \\
\text { every Irish Setter dog that they had owned in the previous ten years. } \\
\text { This poses a number of related issues for the data: } \\
\text { - The dogs may not still be alive. Thus, it is not clear how the } \\
\text { owners of the dogs not affected (the control dogs) could } \\
\text { complete the questionnaire as per the instructions as the } \\
\text { dogs may have been dead at the time of completion. Do the } \\
\text { owners then complete the form based on the management, } \\
\text { exercise, feeding, etc routines of the dog shortly before it } \\
\text { died, or when it was younger/fitter/healthier? If the owners } \\
\text { all elect for the form (as the closest point to 'current') this } \\
\text { could introduce significant biases into the data set. } \\
\text { Up to ten years ago, is a long time to expect owners to } \\
\text { accurately reflect back and recall their dogs feeding, } \\
\text { exercise, housing regime, and so on. As the GDV group } \\
\text { owners were asked to recall this information from the time } \\
\text { the dog had its first episode of GDV, the length of time the } \\
\text { owners were required to reflect back could be even longer. } \\
\text { The questionnaire is not sensitive to variations in feeding } \\
\text { regime. For example, the diet type fed may vary from day to } \\
\text { day, or over a longer time frame. Thus, any risk factor } \\
\text { identified may be arbitrary and true risk factors may not be } \\
\text { identified. }\end{array}$ \\
\hline \multicolumn{2}{|l|}{ Raghavan (2004) } \\
\hline Population: & $\begin{array}{l}\text { Dogs (male, female, neutered and entire) from eleven different large } \\
\text { and giant dog breeds (Akita, Bloodhound, Collie, Great Dane, Irish } \\
\text { Setter, Irish Wolfhound, Newfoundland, Rottweiler, Saint Bernard, } \\
\text { Standard Poodle, and Weimaraner), that were located within the } \\
\text { USA. Dogs were required not to have a medical history that included } \\
\text { an episode of GDV. }\end{array}$ \\
\hline Sample size: & $\begin{array}{l}318 \text { dogs: } \\
-\quad 106 \text { dogs that developed a GDV } \\
-\quad 212 \text { dogs that did not develop a GDV (the control group) }\end{array}$ \\
\hline Intervention details: & $\begin{array}{l}\text { This study used dogs drawn from a larger study (Glickman, et al., } \\
\text { 2000). The methodology for this study was as follows: } \\
\text { The study began in June } 1994 \text { and ended in February } 1999 . \\
\text { Therefore, the maximum possible period that a dog could be studied } \\
\text { for was } 58 \text { months. } \\
\text { Dogs were recruited through breed clubs and dog shows. At the start } \\
\text { of the study, owners were asked about the presence of GDV in the } \\
\text { medical history of the dog or any of its first-degree relatives. The dog } \\
\text { was physically assessed for body condition and temperament, and } \\
\text { conformational measurements taken. }\end{array}$ \\
\hline
\end{tabular}


Within thirty days of recruitment, owners were provided with a detailed questionnaire to complete that provided data on the dog's GDV history (if positive, the dog was excluded), breeding, medical history, reproductive status, personality and temperament, and dietary factors.

Owners were instructed to notify the researchers if any of the following outcomes occurred:

- $\quad$ The dog developed a GDV (if so, the researcher confirmed this with the veterinarian who treated the dog)

- $\quad$ The dog died of another cause

- $\quad$ The ownership of the dog was transferred to another person

Owners were contacted in 1997, 1998, and 1999 to find out if, over the duration of the study, their dog had developed a GDV and, if so, whether the dog died or survived.

1991 dogs were registered at the initial state (dog show). Of these, 77 were excluded due to a previous history of GDV. The remaining dogs ( $n=1914$ ) were enrolled on the study, of these, at least one follow up was obtained for 1843 dogs and the detailed questionnaire was completed for 1660 . Of the latter group, 23 were excluded for being less than six months old at the start. This left 1637 dogs o be included in the analysis of this study.

At the end of that prospective study, there was sufficient information on diet and 'vital status' (not defined by authors, presumed to be GDV development and other demographic information matched for in the current study), for 1634 dogs (of the $1637)$ to be potentially included in this study. Of these, all dogs that developed a GDV $(n=106)$ were included.

Dogs that developed a GDV during the prospective study were divided into six groups based upon the calendar year in which they developed a GDV (1994 - 1999*). The control group ( $n=212)$ was then randomly selected to ensure that for each year, for each GDV dog there were two control dogs that had been alive the year that the GDV dog developed a GDV but who never themselves developed a GDV.

*Nb. The original study (Glickman et al. 2000) states $1994-1999$ (which would be six calendar years). The current study refers to "follow - up ended in December 2000" (pg. 193) and six consecutive calendar years of $1994-2000$. However, it then directs the reader back to the detailed study methodology described in the Glickman et al. 2000 study for further details. This study does not refer to follow 


\begin{tabular}{|c|c|}
\hline & $\begin{array}{l}\text { up data in } 2000 \text { and, indeed the study was published in January } \\
2000 \text {. Thus, it is assumed that the current authors mean } 1994- \\
1999 .\end{array}$ \\
\hline Study design: & Case-control study. \\
\hline Outcome studied: & $\begin{array}{l}\text { The outcome measure was whether the dog developed an episode } \\
\text { of GDV during the course of the study and whether it survived this } \\
\text { episode. The study then looked for factors that were associated with } \\
\text { an increased risk of developing GDV in the population studied. } \\
\text { Of direct relevance to this PICO, the authors' asked the owners } \\
\text { about: } \\
\text { - The diet type fed to the dog (dry, canned, semi-moist, } \\
\text { unprocessed, home-prepared [raw versus cooked], table } \\
\text { scraps, treats) } \\
\text { Of potential relevance to this PICO, the authors' also asked: } \\
\text { - Whether food was moistened before feeding }\end{array}$ \\
\hline $\begin{array}{l}\text { Main findings: } \\
\text { (relevant to PICO question): }\end{array}$ & $\begin{array}{l}\text { There was no significant effect on diet type on risk of GDV. } \\
\text { - All of the dogs that developed a GDV ( } n=106) \text { and all, bar } \\
\text { two, of the control dogs }(n=210) \text { were fed a dry diet as their } \\
\text { primary diet type. } \\
\text { - The median (range) percentage of metabolisable energy } \\
\text { derived from the dry component of the diet was similar } \\
\text { between controls }(97.1,0-100) \text { and GDV cases }(96.1,59.5- \\
\text { 100) }(P=0.99) \text {. } \\
\text { - Primary was defined as the dog obtained }>50 \% \text { of its } \\
\text { metabolisable energy from this food type. } \\
\text { There was no effect of moistening the kibble on GDV risk }(P>0.25) \text {. }\end{array}$ \\
\hline Limitations: & $\begin{array}{l}\text { Failure of the authors to report the findings of some of the data } \\
\text { referred to in the methods section limits the ability to interpret } \\
\text { some of the findings or draw conclusions. } \\
\text { The authors collect data on diet type fed at the start of the study } \\
\text { (within } 30 \text { days of recruiting dogs). No further attempts were made } \\
\text { to collect further data on this at regular intervals. Thus, unless diet } \\
\text { type fed is static and does not change over time, this reduces the } \\
\text { ability of the study to detect real effects or meaningfully explain the } \\
\text { effects observed. } \\
\text { All the dogs in the study (bar two) were fed dry food as the primary } \\
\text { diet type. Therefore, it is not clear how the study could evaluate } \\
\text { kibble as a risk factor as there were inadequate numbers of dogs in } \\
\text { each group (i.e. none in the GDV group and two in the no GDV } \\
\text { control group) fed an alternative diet type. }\end{array}$ \\
\hline
\end{tabular}




\begin{tabular}{|c|c|}
\hline \multicolumn{2}{|l|}{ Uhrikova (2015) } \\
\hline Population: & $\begin{array}{l}\text { Dogs }{ }^{*} \text { owned by people who could read either Czech or Slovak } \\
\text { language. The survey was distributed within the Czech Republic } \\
\text { through various websites aimed at dog owners, some veterinary } \\
\text { clinics and dog shows, and by emailing owners through kennel and } \\
\text { large breed kennel club websites. However, survey distribution was } \\
\text { not restricted to the Czech Republic, so respondents came from a } \\
\text { wider geographic area, though predominantly Czech }(90.7 \% \text { of } \\
\text { respondents). } \\
\text { 'The control dogs were dogs older than } 5 \text { years, and weighing > 30kg } \\
\text { and/or taller than } 50 \mathrm{~cm} \text {, and had not had a gastroplexy performed. } \\
\text { It is not clear whether the same restrictions applied to the two GDV } \\
\text { groups (see below). However, it should be noted that, in the results } \\
\text { section, the study population overview indicates that this weight } \\
\text { restriction must have been lifted as the minimum weight in the } \\
\text { control, GDV - survivor, and GDV - died groups was } 17 \mathrm{~kg}, 20 \mathrm{~kg} \text {, and } \\
17 \mathrm{~kg} \text { respectively (see limitations). }\end{array}$ \\
\hline Sample size: & $\begin{array}{l}785 \text { usable responses: } \\
\text { - Control group: } 536 \text { dogs } \\
\text { - Survived GDV group: } 127 \text { dogs } \\
\text { - } \quad \text { Died from the GDV group: } 122 \text { dogs }\end{array}$ \\
\hline Intervention details: & 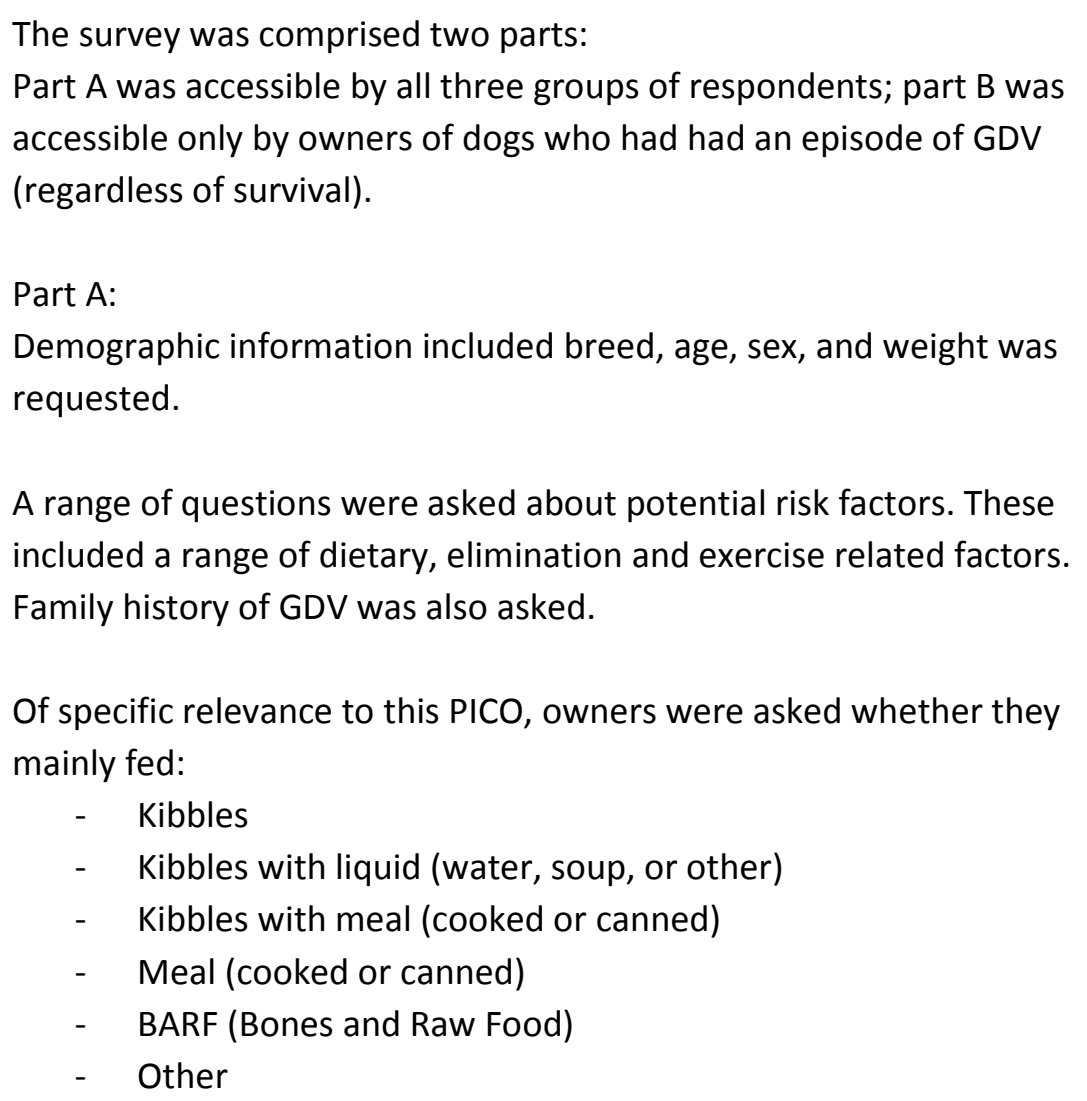 \\
\hline & For the purpose of analysis, the diets fed were merged into the \\
\hline
\end{tabular}




\begin{tabular}{|c|c|}
\hline & 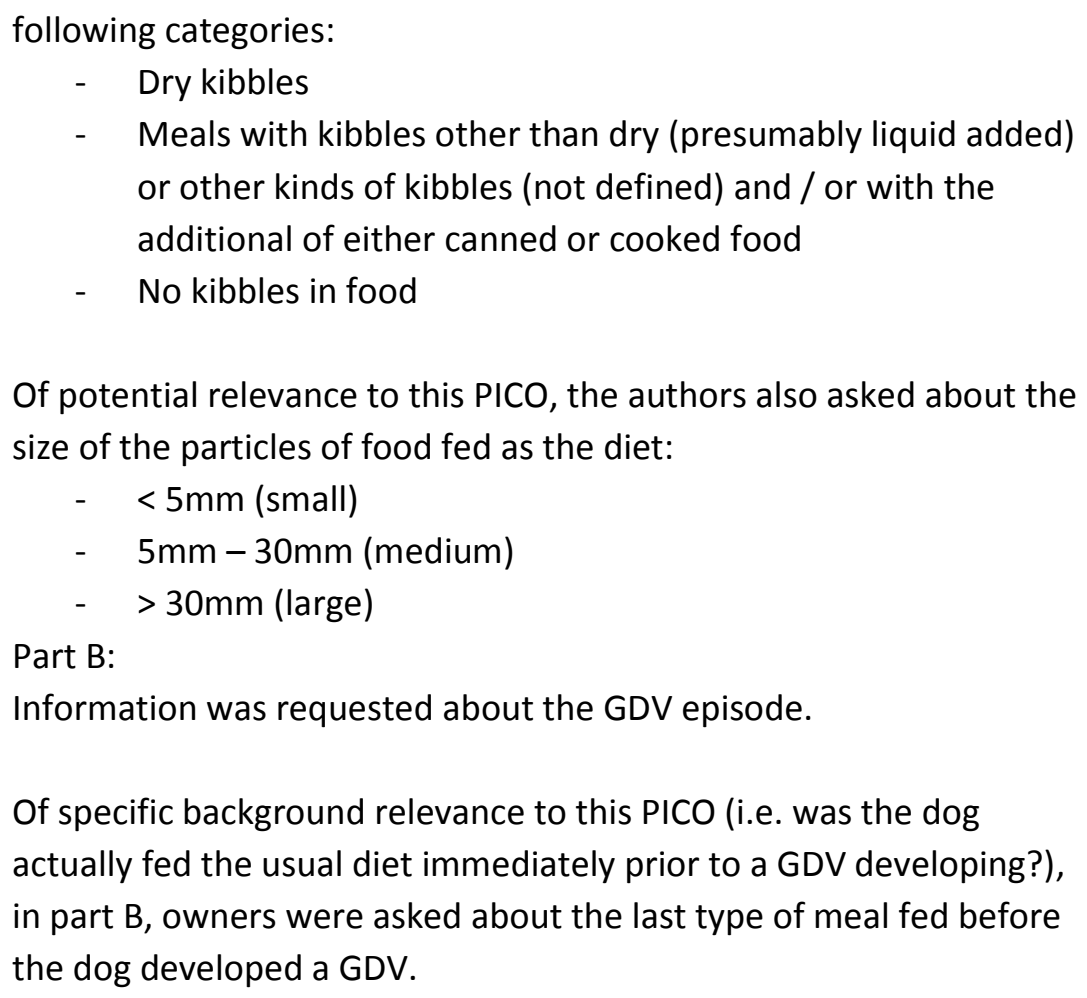 \\
\hline Study design: & A cross sectional study. \\
\hline Outcome studied: & $\begin{array}{l}\text { The outcome variable was a) episode of GDV (yes/no?), and, b) of } \\
\text { dogs that developed a GDV, survived or died? The study then looked } \\
\text { for risk factors that were associated with these outcomes. } \\
\text { Of specific relevance to this PICO, the authors looked at different } \\
\text { diet types normally fed as potential risk factors for GDV } \\
\text { development. They also examined the type of diet last fed before } \\
\text { the dog developed a GDV. Of potential relevance, they also asked } \\
\text { owners about the size of the particles of food that comprised the } \\
\text { dog's diet. } \\
\text { In the analysis, in calculation of the odds ratios, the relative risk } \\
\text { associated with feeding a diet with small or large particles was } \\
\text { compared to that of dogs fed a diet in which the maximum size fed } \\
\text { was medium sized particles. }\end{array}$ \\
\hline $\begin{array}{l}\text { Main findings: } \\
\text { (relevant to PICO question): }\end{array}$ & $\begin{array}{l}\text { Part A of the questionnaire: } \\
\text { Dogs fed a dry kibble diet only were no more likely to have a GDV } \\
\text { episode than dogs fed other diet types/combinations (Odds ratio: } \\
1.111,95 \% \text { confidence interval: } 0.802-1.539, P=0.527 \text { ) } \\
\text { Dogs fed diets that did not contain any kind of kibble were } \\
\text { significantly less likely to have a GDV than dogs fed a diet containing } \\
\text { kibbles (dry kibbles, kibbles and canned food, or kibbles and cooked } \\
\text { food) (Odds ratio: } 0.486,95 \% \text { confidence interval: } 0.283-0.834, P=\end{array}$ \\
\hline
\end{tabular}




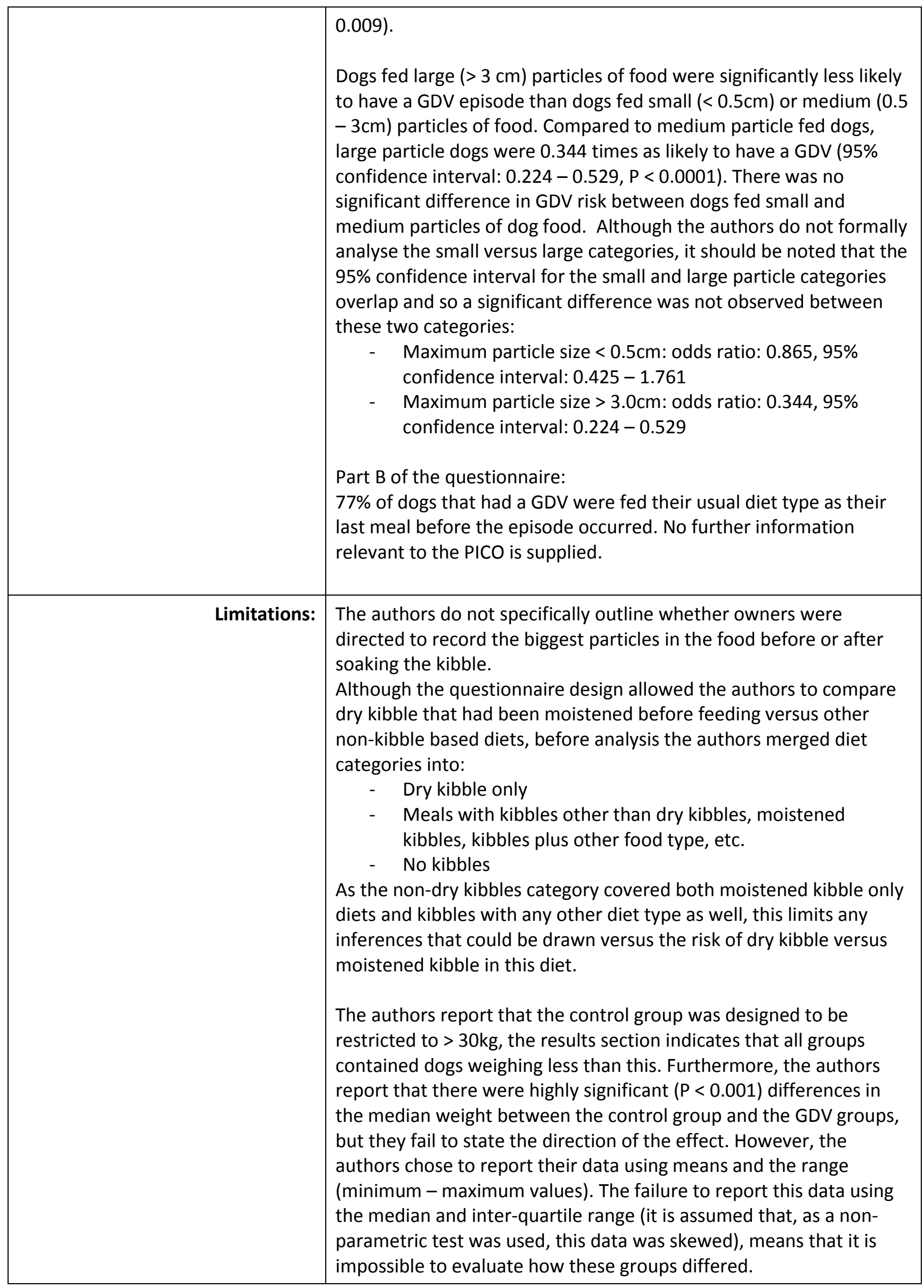




\section{Appraisal, application and reflection}

Six studies were identified that purported to address the PICO either partially or fully. The findings of these studies were mixed and of variable quality. However, no studies found that feeding kibble as a protective factor reduced the risk of an episode of GDV. Teasing out the different potential aspects to this PICO (e.g. dried kibble per se versus other diets; dry kibble versus moistened kibble, or diet fed immediately prior to GDV versus the usual diet fed) was difficult or impossible to evaluate due to limitations or differences in the study design. In some cases, diet type was described in terms of maximum particle size present in the diet, rather than diet type. These studies and information have been included for the following reasons: the author is unaware of any kibble diets that have kibbles that are bigger than $30 \mathrm{~mm}$; the authors report that any diet containing the largest particles contained non-kibble components (thereby fulfilling the inclusion criterion); the authors report other information that makes clear that some of these diet sizes were kibble based.

Two studies should be removed from consideration before drawing any inference about the risk of GDV posed by feeding a dried kibble diet (moistened and/or fed dry) per se. The first of these, Glickman et al. (1997), intended to evaluate kibble as a risk factor, but found that almost all owners reported feeding their dog (irrespective of whether the dog was in the GDV or control group) mainly a kibble diet. The authors rightly note that, consequently, it was not possible to evaluate a dried kibble diet per se as a risk factor for GDV as there is no comparator (for example, of non-kibble fed dogs, what proportion develop a GDV compared to dogs fed a kibble diet?). It should be noted though that this study did identify the addition of table scraps to a dog's diet was a protective factor: dogs fed partially on table scraps had a significantly reduced risk of GDV of 59\%. The study design does not allow the reader to tease apart the owner feeding regimes further so it is difficult to evaluate the impact of this finding in relation to the PICO. However, this aspect of the study does not suffer from a lack of comparator so this finding should be taken forward to the final evaluation. Although Ragahavan et al. (2004) report that there was no significant effect of feeding kibble on risk of GDV, this study suffers from the same limitation as the Glickman et al. (1997) study as all, bar two, of the dogs included were primarily fed on a kibble-based diet. The authors do extend their analysis by exploring the proportion of metabolisable energy derived from the kibble component of the diet (to account for mixed diet type feeding) to demonstrate that the proportions do not vary between groups, but this does not remove the limitation described here.

Of the remaining four studies, the Pipan et al. (2012) study reports an impressive sample size (GDV group: $\mathrm{n}=1114$; Control group: $\mathrm{n}=1437$ ) and reports that feeding a kibble diet significantly increases the risk of GDV. However, the population that the authors elected to study was not restricted to large and giant breeds/sized dogs (i.e. those which are considered to be at high risk of GDV). As the authors do not report requesting information about the body weight of the dogs included in the survey, and there is no evidence to suggest this in the results section, it is not possible to evaluate whether the two groups of dogs varied significantly across this potentially important dimension. Consequently, the study findings should be approached with caution as a potential source of relevant bias has been introduced into the methodology if large and giant breeds are more likely to be fed a kibble based diet than small and medium sized breeds. As a dried kibble diet tends to cost less than commercial diets containing a higher moisture content, and big dogs cost more to feed than small dogs, the supposition of bias is reasonable. However, this study does also identify fish and egg-based dietary supplements (but not table scraps) as a highly significant protective factor against risk of GDV in dogs. Whether this finding is also a potential artefact of the sample population is not necessarily clear, as the exact nature and form of the supplements is not clear. Are smaller dogs more or less likely to be given supplements?

Uhrikova et al. (2015) also identified a dried kibble diet as part or all of the diet (but not dry, no liquid added before feeding, kibble only versus other diet combinations) as a risk factor for GDV compared to feeding a diet that contained no kibbles at all, however their study potentially suffers from the same criticism as the 
Pipan et al. (2012) study. Although Uhrikova et al. (2015) appear to be alert to the bodyweight issue (their target control group definition attempted to restrict respondents to dogs weighing $>30 \mathrm{~kg}$ only), they were unsuccessful in achieving this. All groups of dogs included dogs lighter than $30 \mathrm{~kg}$, but a highly significant difference was observed in bodyweight between the control group and the two GDV groups (survived versus died). However, the authors fail to state the direction of effect and their choice of measure of variation (range) and central tendency (the mean is reported, despite using a non-parametric test to compare what was presumably skewed data) does not allow the reader to assess the impact of this difference. As a consequence, the findings of this study should also be viewed with caution in relation to the PICO. Uhrikova et al. (2015) also found that a diet with particles of food in which the maximum size was $>3 \mathrm{~cm}$ was a protective factor that reduced the risk of GDV compared with a diet containing diets in which the maximum particle size was $0.5-3 \mathrm{~cm}$, but significant differences between the smallest particle sized diets $(<0.5 \mathrm{~cm})$ and the largest $(>0.3 \mathrm{~cm})$ were not observed.

Of the remaining studies, the Elwood (1998) study most closely primarily addresses the PICO. Although a smaller sample size than some other studies (GDV dogs: $n=75$; control dogs: $n=594$ ), the methodology utilised by this study allowed the authors to examine the risk of feeding a kibble diet per se compared with other diet types, and the effect of the kibble diet being fed dry or moistened. The initial univariate analysis identified kibble as a potential risk factor; however, once other potential risk factors were built into the multivariate analysis, this potential risk factor was no longer significant. The primary issue with this study is that the authors requested that owners complete the form for any/all Irish Setter dogs that they had owned in the previous 10 years (regardless of whether they had had an episode of GDV or not). As owners of dogs that had had a GDV were instructed to answer the form by providing details of the dogs' diet prior to the GDV episode, some owners may have had to recall back an even longer period of time. Unless dogs are generally fed a relatively unvarying diet type over an extended period of time, this may reduce the value of owner recollection over such a long-time frame. The authors do not report data to allow the reader to evaluate whether the two groups differed across the dimension of 'how long ago the dog was last owned/alive' (or similar) to see if the demographics were similar between groups across this potential dimension. The remaining study (Theyse et al., 1998) suffers from the same limitation in relation to the GDV group as they retrospectively searched records over a 13-year time span, for GDV cases (which may have died many years ago) and then contacted these owners to obtain, firstly, diet fed to the dog, and secondly, a sample of this diet. This was compared to a control group recruited through a breed society. This study identified feeding a diet with a maximum particle size of $>30 \mathrm{~mm}$ were significantly less likely to have a GDV than dogs fed a diet containing a maximum particle size less than $<5 \mathrm{~mm}$ (of which 19 of the 23 dogs in this category were fed a dry kibble diet only). If historical differences in trends in the type of diet fed were present (e.g. if dogs were more likely to be fed a raw diet in present time (at the time the study was conducted) than over the 13-year time frame studied, then this could have skewed the data in the direction described as the present-day dogs would have been primarily control group dogs. Uhrikova et al. (2015) also found that feeding large particles of food had a protective effect against GDV and this study did not suffer the Theyse et al. (1998) limitation described. However, the strength of the Uhrikova et al. (2015) study in supporting the Theyse et al. (1998) finding is weakened by the lack of transitive inference in their data, as no other size categories were significant (i.e. small > medium, and crucially small > large were not identified as relative risk factor relationships).

In conclusion, most of the studies that form a part of this PICO contained limitations that meant that they cannot specifically address the PICO due to a lack of comparator (Glickman et al., 1997; Ragahavan et al., 2004), or viewed with considerable caution with regards to any significant effect of kibble feed due to issues with the population surveyed or reported (Pipan et al., 2012; Uhrikova et al, 2015). Of the remaining two studies, the findings are not in agreement with one study (Theyse et al. 1998) concluding that there was no effect of kibble, and one concluding that, relative to feeding diets with large particles, diets that were small particle sized (mainly dry kibble only feeders) were significantly more likely to experience a GDV. However, the long time frame over which owners were potentially asked to recall back (Theyse et al., 1998; Elwood, 1998), and the requesting of a diet sample for a dog that may have died up to 13 years ago (Theyse et al, 
1998) mean that these findings should not be accepted uncritically. However, the Glickman et al. (1997) finding that table scraps significantly reduced the risk of GDV does provide some support for the alternative claim that feeding alternative diets may be a protective factor. However, there is a need for further research in this area, with adequate numbers of dogs being fed specific, identifiable, alternative diets (e.g. primarily raw, primarily home-made cooked, etc) in order for these hypotheses to be tested. The preponderance of dogs being fed primarily a kibble diet (based on the studies evaluated) may make this more problematic to investigate. Though as a consequence, the balance of unevaluated evidence supports the claim that kibble is a risk factor for GDV (and that non-kibble based diets or kibble plus non-kibble supplements or dietary additions may be a protective factor that reduces the risk of GDV), in practice, there is insufficient adequately controlled evidence to demonstrate this clearly.

\section{Methodology Section}

\begin{tabular}{|c|c|}
\hline \multicolumn{2}{|l|}{ Search Strategy } \\
\hline $\begin{array}{r}\text { Databases searched and dates } \\
\text { covered: }\end{array}$ & $\begin{array}{l}\text { Pubmed; Science Direct (all years, restricted to journals); Web of } \\
\text { Science; CAB Abstracts. (1973-2016). }\end{array}$ \\
\hline Search terms: & $\begin{array}{l}\text { (dogs OR dog OR canine OR canines OR canid OR canis OR bitch) } \\
\text { AND ("gastric dilatation" OR "gastric dilation" OR "gastric dilatation } \\
\text { volvulus" OR GDV OR "gastric torsion" OR "stomach volvulus") AND } \\
\text { (feed* OR diet OR diets OR dietary OR food OR kibble) }\end{array}$ \\
\hline Dates searches performed: & $29^{\text {th }}$ March 2017 \\
\hline
\end{tabular}

\section{Exclusion / Inclusion Criteria}

\begin{tabular}{|l|l|}
\hline Exclusion: & $\begin{array}{l}\text { Pre-defined exclusion criteria: non-English language, popular press } \\
\text { articles. }\end{array}$ \\
\hline Inclusion: & $\begin{array}{l}\text { Any comparative (control group utilised) study in which the effect } \\
\text { of diet type on development of a gastric dilatation (+/- volvulus) } \\
\text { was investigated. }\end{array}$ \\
& $\begin{array}{l}{ }^{*} \text { Diet type must refer to a dry or kibble based diet, plus at least one } \\
\text { other type of diet in order for the study to be included. }\end{array}$ \\
\hline
\end{tabular}




\begin{tabular}{|c|c|c|c|c|c|c|}
\hline \multicolumn{7}{|c|}{ Search Outcome } \\
\hline Database & $\begin{array}{c}\text { Number } \\
\text { of } \\
\text { results }\end{array}$ & $\begin{array}{l}\text { Excluded } \\
\text { - did not } \\
\text { address } \\
\text { the PICO }\end{array}$ & $\begin{array}{c}\text { Excluded - not } \\
\text { English } \\
\text { language }\end{array}$ & $\begin{array}{l}\text { Excluded - } \\
\text { conference } \\
\text { abstract only }\end{array}$ & $\begin{array}{l}\text { Excluded - } \\
\text { duplication }\end{array}$ & $\begin{array}{c}\text { Total } \\
\text { relevant } \\
\text { papers }\end{array}$ \\
\hline NCBI PubMed & 35 & 30 & 0 & 0 & 0 & 5 \\
\hline $\begin{array}{l}\text { Thomson } \\
\text { Reuters Web } \\
\text { of Science }\end{array}$ & 35 & 28 & 1 & 0 & 5 & 1 \\
\hline CAB Direct & 58 & 50 & 1 & 1 & 6 & 0 \\
\hline Science Direct & 343 & 343 & 0 & 0 & 0 & 0 \\
\hline \multicolumn{6}{|c|}{ Total relevant papers when duplicates removed } & 6 \\
\hline
\end{tabular}

\section{CONFLICT OF INTEREST}

The author declares no conflict of interest.

\section{REFERENCES}

1. Elwood, C. (1998) Risk factors for gastric dilatation in Irish setter dogs. Journal of Small Animal Practice, 39 (4), pp. 185 - 190. http://dx.doi.org/10.1111/j.1748-5827.1998.tb03627.x

2. Glickman, L. et al. (1997) Multiple risk factors for the gastric dilatation - volvulus syndrome in dogs: a practitioner / owner case - control study. The Journal of the American Animal Hospital Association, 33 (3), pp. 197 - 206. http://dx.doi.org/10.5326/15473317-33-3-197

3. Glickman, L. Glickman, N. Schellenberg, D. et al. (2000) Incidence of and breed - related risk factors for gastric dilatation - volvulus in dogs. Journal of the American Veterinary Medicine Association, 216 (1), pp. 40 - 45. http://dx.doi.org/10.2460/iavma.2000.216.40

4. Pipan, M. Brown, D. Battaglia, C. et al. (2012) An internet - based survey of risk factors for surgical gastric dilatation - volvulus in dogs. Journal of the American Veterinary Medicine Association, 240 (12), pp. 1456 - 1462. http://dx.doi.org/10.2460/javma.240.12.1456

5. Raghavan, N. Glickman, N. McCabe, G. et al. (2004) Diet - related risk factors for Gastric Dilatation Volvulus in dogs of high risk breeds. Journal of the American Animal Hospital Association, 40 (3), pp. 192 - 203. http://dx.doi.org/10.5326/0400192 
6. Theyse, L. van de Brom, W. and van Sluijs, F. (1998) Small size of food particles and age as risk factors for gastric dilatation volvulus in Great Danes. Veterinary Record, 143 (2), pp. 48 - 50.

http://dx.doi.org/10.1136/vr.143.2.48

7. Uhrikova, I. Machackova, L. Rauserova - Lexmaulova, L. et al. (2015) Risk factors for gastric dilation and volvulus in central Europe: an internet survey. Veterinarni Medicina, 60 (10), pp. $758-587$. 


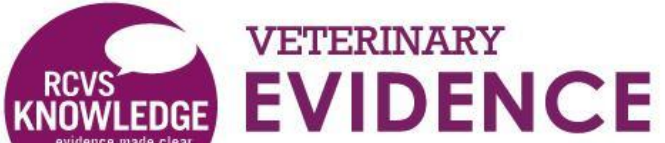 \\ orthe}

\section{Intellectual Property Rights}

Knowledge Summaries are a peer-reviewed article type which aims to answer a clinical question based on the best available current evidence. It does not override the responsibility

of the practitioner. Informed decisions should be made by considering such factors as individual clinical expertise and judgement along with patient's circumstances and owners' values. Knowledge Summaries are a resource to help inform and any opinions expressed within the Knowledge Summaries are the author's own and do not necessarily reflect the view of the RCVS Knowledge.

Authors of Knowledge Summaries submitted to RCVS Knowledge for publication will retain copyright in their work, but will be required to grant to RCVS Knowledge an exclusive license of the rights of copyright in the materials including but not limited to the right to publish, re-

publish, transmit, sell, distribute and otherwise use the materials in all languages and all media throughout the world, and to license or permit others to do so.

Authors will be required to complete a license for publication form, and will in return retain certain rights as detailed on the form.

Veterinary Evidence and EBVM Network are RCVS Knowledge initiatives. For more information please contact us at editor@veterinaryevidence.org

RCVS Knowledge is the independent charity associated with the Royal College of Veterinary Surgeons (RCVS). Our ambition is to become a global intermediary for evidence based veterinary knowledge by providing access to information

that is of immediate value to practicing veterinary professionals and directly contributes to evidence based clinical decision-making.

\section{www.veterinaryevidence.org}

RCVS Knowledge is a registered Charity No. 230886. Registered as a Company limited by guarantee in England and Wales No. 598443.

Registered Office:

Belgravia House

62-64 Horseferry Road

London SW1P 2AF 